UDK: 336.711

DOI: $10.1515 / j c b t p-2016-0025$

\author{
Ahmad-Reza Jalali Naini * \\ Mohammad-Amin Naderian **
}

\section{Over-reaction to Policy Signals, and Central Bank Optimal Communication Policy}

\author{
* Institute for management and \\ planning studies, Tehran \\ E-mail: \\ ahmad_jalali@hotmail.com \\ ${ }^{* *}$ Ph.D student at Allameh \\ Tabatabaei University, Tehran \\ E-mail: \\ Naderian.amin@gmail.com
}

\begin{abstract}
This paper reviews the theoretical arguments and counter arguments regarding central bank optimal communication policy in an environment with imperfect common knowledge and strategic complementarity. More specifically, the paper discusses the environment in which full transparency is no longer necessarily the superior strategy. Uncertainty about the underlying economic state in the presence of dispersed information is the basis for the emergence of imperfect common knowledge. These issues are further discussed in an augmented Lucas-island model. Full policy transparency in this setting leads to overreliance to central bank public policy signals, resulting in the expectations coordination away from fundamentals - dubbed as over-reaction to central bank announcements. Optimal communication policy in this context entails strategies to limit overreaction via partial transparency or partial publicity.
\end{abstract}

Key Words: Optimal communication policy, imperfect common knowledge, strategic complementarity, full transparency.

JEL Classification: E52, E58, D82.

\title{
Introduction:
}

Uncertainties regarding short to medium policy intentions of the Fed and the future course of policy rates, known as "signalling shocks", resulted in substantial market volatility since the public could not fully and transparently read the 
Fed's policy signals. ${ }^{1}$ Overreaction of financial markets to Federal Reserve decision to gradually unwind its abnormally accommodative stance was followed by significant market volatility in the US and had far reaching implications in the emerging economy financial markets and the magnitude of capital flows in these countries. In the era of inflation targeting, full transparency was supposed to be one of the pillars of this framework. However, the presence of information dispersion (lack of common knowledge) and the related discussions questioned optimality of full transparency in the presence of signalling shocks.

There is an implicit assumption embedded in most economic (and policy) models that policy makers and the public have a common information set. However, in the more realistic decentralized economic activity, economic agents do not make their decisions based on the same beliefs (information set). This information dispersion is considered to be one of the most important problems for policy making (Hayek, 1945). In the basic incomplete information models proposed by Phelps (1970) and formalized by Lucas (1972), firms and households have information only about their own activities but are incompletely informed about the effect of monetary shocks on the aggregate price level. In this environment, assuming common information set among islanders and common knowledge about monetary policy shocks, economic agents are unable to distinguish between the temporary and permanent effects of an unanticipated exogenous monetary shock on local relative prices - even if the shock is observed by all islanders. This is because they cannot attribute the above mentioned relative price changes to local or aggregate monetary conditions. In consequence, unanticipated monetary shocks have real effects and can play the role of impulse mechanism in monetary business cycles. Sluggish adjustment of prices owing to incomplete information about the aggregate variables is the underlying propagation mechanism in this model.

Although a canonical Lucas-Phelps model introduces incomplete information as a source of business cycle, it assumes common information among islanders and thus perfect common knowledge. Note that what drives (and is the source of) business cycle fluctuations in this setting is an exogenous unanticipated monetary shock. In the more complex theories of incomplete information, it is assumed that the information set for economic agents are not the same. Under this circumstance, optimal decision making with rational expectation requires that agents formulate the so-called higher order expectations, i.e. beliefs about the belief of others and belief about what the others believe about others, and so on. This situation transpires owing to the dependence of optimal price determina-

1 For more details on this and the ramifications of that on the global economy see Arora et al (2014). 
tion of an individual on the price set by others. Ui (2003) shows that in this information structure where, apart from public signals, private signals enter decision process regarding equilibrium quantities due to dispersed information sets. In this situation, monetary shocks could have real effects through both anticipated (imperfect common knowledge effect) and unanticipated (as in the canonical Lucas island) effects. In other words, we have a combination of an endogenous business cycle (sunspot equilibrium ${ }^{2}$ ) along with exogenous monetary impulse mechanism.

It is widely perceived that stabilization of monetary business cycles generated under incomplete information and imperfect common knowledge can be achieved through completely transparent policy to disclose information publicly available to everyone. Helwig (2002) and Morris and Shin (2002) (henceforth MS (2002) proposed a Lucas-Phelps model with both private and public signals in order to evaluate the social value of public information. Their results show that public information can accelerate the price adjustment and reduce real effects of monetary shocks through coordination among heterogeneously informed agents. However, introducing complementarity in payoffs to the agents (islanders) may generate overreaction to public announcements which may increase real output fluctuation under certain conditions. In this setting, MS (2002) argue that a completely transparent communication policy is not necessarily the optimal one.

In the model proposed by MS (2002), if economic agents are persuaded that central bank's announcements (as a sunspot) can coordinate expectations about interest rates and prices, then central bank (CB) has a ready-made signalling instrument, that is, information or announcements by $\mathrm{CB}$ are believed by the public, hence influence outcomes. The effectiveness of central banking announcements as sunspots entails that CB statements have the same general features as the sunspot signal just mentioned. That is, not only all agents can observe it, but it also needs to be an observable common knowledge for all. Moreover, there should be common knowledge of the exact meaning of the policy statement for all economic agents. If so, CB policy communications must be transparent (MS 2002).

2 The rational expectation forecast errors in linear rational expectation models are due to two sources, namely, the fundamental shocks and a vector of sunspot shocks. If the forecast error is expressed as a function of the exogenous fundamental shocks, there will be a unique stable (saddle path) solution for the linear rational expectation model because it eliminates explosive components of endogenous variables such as price. In other words, the solution is unique if the mapping from fundamental exogenous shocks to forecast errors is one-to-one. On the other hand, if the fundamental shocks fail to completely explain the rational expectation forecast errors, the forecast error will be a function of sunspots as well. In this case, linear rational expectation model is indeterminate (Sink) and we encounter multiple equilibrium. 
In this environment of perfect common knowledge, $\mathrm{CB}$ announcements have a dual role: information dissemination and coordination. On one hand, announcements are an instrument for communicating (public) information regarding CB's current views on the economy as well as current and future policy actions, say, regarding interest rates. In this capacity $\mathrm{CBs}$ should be transparent in their announcements. On the other hand, $\mathrm{CB}$ communications are also a focal point for economic actors and functions as a coordination instrument regarding fundamental variables, e.g. interest rates, exchange rates, etc.

In an environment of imperfect common knowledge, the above referred twin role can entail unintended consequences. ${ }^{3}$ On one hand, effective signalling can promote coordination powers of $\mathrm{CB}$ to guide public belief towards fundamentals. On the other hand, its effectiveness in this capacity has the potential to create market disturbances if expectations are coordinated actions away from fundamentals (Amato and Morris 2006). If the public puts a large weight on public signals in forming their expectations on fundamentals, then there is a possibility of overreaction to public (CB) signals (announcements) and magnified harm caused by public signal noise. Hence, the value of public information should be assessed by its dual role of sending fundamental information and as a central reference for improved coordination. Svensson (2006) argues that the necessary condition for the emergence of overreaction, hence the case against full transparency, is far from reality. For transparency to be harmful to welfare in MS (2002), central bank information has to be less accurate than private information. ${ }^{4}$ Morris, Shin and Tong (2006) respond to this criticism by incorporating correlated signals in their analysis and by showing that the result holds even if the public signal is more accurate than the private signals.

While the debate between MS and Svensson focuses on two extreme cases of information disclosure, full transparency vs. full opacity, Cornand and Heinemann (henceforth CH (2008)) and Baeriswyl (2011) show that "limiting information publicity" improves welfare by reducing the degree of common knowledge and thus limits the overreaction of agents to public policy signals. The theoretical literature envisages two disclosure strategies for reducing the overreaction of market participants to public information: partial publicity and partial transparency. The first one consists of disclosing the transparent information to a fraction

3 Plausibly, when CB has perfect foresight and there is no information cost, no harm is associated with CB's role as a social planner.

${ }^{4}$ It is safe to assume that the information available to public institutions is generally more accurate than information available privately. At the very least, all CBs have invested heavily in databases and human capital. 
of market participants only (CH 2008). The degree of publicity is determined by the fraction of market participants who are allowed to receive the public signal. Choosing a communication channel which does not reach all market participants reduces overreaction to $\mathrm{CB}$ disclosures as uninformed participants cannot react to it, whereas informed participants react less strongly as they know that some of their peers are uninformed. The second strategy consists of disclosing ambiguous public information to all market participants (Heinemann and Illing 2002). The degree of transparency is determined by idiosyncratic inaccuracy of the public signal disclosed to all market participants. Communicating with ambiguity reduces overreaction since it entails uncertainty about how other market participants interpret the disclosure, which mitigates its signalling role.

This paper attempts to examine the debate surrounding the issue of optimal communication in central banks. The issue involves complete transparency under rational expectation, along with perfect common knowledge. Transparent communication policy is a general feature of the standard inflation targeting framework. However, its universal applicability has come under question for the non-universality of the underlying perfect common knowledge assumption. By replacing the information structure with imperfect common knowledge under rational expectation, the critics obtain a different policy implication. In this paper we further develop the Lucas-Phelps island economy model in a situation of imperfect common knowledge. The latter is derived from more realistic assumptions regarding uncertainty about the underlying state of the economy and the existence of strategic complementarity among agent actions. This setting results in solutions that point to sub-optimality of complete transparent communication policy. The interesting and non-trivial result from the model suggests that partial transparent communication policy is superior under certain circumstances.

The next section formalizes the discussion on CB communication policy in an environment of imperfect common knowledge arising from strategic complementarities amongst economic agents and uncertainty regarding economic fundamentals (MS 2002). This is done in the context of a Lucas-island model that shows how higher order beliefs can result in overreaction to public signals. In conjunction with this discussion, we present differing views on the degree of transparency by the Central Bank (CB). MS (2002) argue that when private information signals have low accuracy and the public signals are associated with imprecision, $\mathrm{CB}$ transparency can have harmful consequences due to overreaction to noise contaminated public signals. ${ }^{5}$ Section three discusses the welfare

5 An example is data announcements by CBs that are frequently, sometimes, substantially revised but at the time of their announcements influence markets. 
implications of public overreactions. Section four provides counter arguments to Morris and Shin by Svensson (2006) and also generalizes Morris and Shin via Baeriswyl (2011) as a response to Svenssons' criticism. Section five provides discussions regarding strategies to limit overreaction to policy signals. Section six provides policy implications based on the issues discussed in the paper.

\section{Overreaction under Imperfect Common Knowledge}

Starting with this section, we discuss the evolution of the debate on optimal communication policy under an environment of imperfect common knowledge. Analytic discussion and evaluation of the issues will be done in the context of a Lucas-Phelps island economy. Here, we have further developed and extended a simple beauty contest set up used by MS(2002), which is a static representation for a variety of settings with incomplete (dispersed) information and strategic complementarity. By casting this model in an island economy model environment (Phelps (1970) Lucas $(1972,1973)$ ) some macroeconomic foundation and structure can be infused to it. Following these papers, assume an economy that consists of a large number of small islands (or distinct geographical regions) with a single (homogeneous) commodity whose supply function in the i island is described by (1).

$$
y_{i}^{s}=b\left[p_{i}-E_{i}\left(\left(\bar{p} \mid \Omega_{i}\right)\right)\right]
$$

Where $y_{i}^{s}$ and $p_{i}$ represent the (natural logarithm) supply and price of the commodity in island (i), $\overline{\mathrm{p}}$ represents the economy-wide average price throughout all islands, and $b>0$ is a parameter. The expectation operator $E_{i}\left(\left(\bar{p} \mid \Omega_{i}\right)\right)$ denotes the expectation of the economy-wide price level given the information available to agents in island (i) depicted by $\Omega_{\mathrm{i}}$. This equation can give rise to an environment wherein strategic complementarity between agents in different islands occurs. Note that residents in island (i) do not exactly know $\bar{p}$ hence they have to form an expectation based on their information set. Output of the good in each island depends on the price of that good in other islands.

The demand for the good in island (i), $\left(\mathrm{y}_{\mathrm{i}}^{\mathrm{d}}\right)$ linearly and inversely is related to the price of the good on island (i). It also depends on the best estimate of an unknown nominal anchor or underlying fundamental (or scale) variable, $\mathrm{m}$, the money supply which is assumed to be controlled by the central bank.

$$
y_{i}^{d}=c\left[E_{i}\left(\left(m \mid \Omega_{i}\right)\right)-p_{i}\right]
$$


Where $\mathrm{c}$ is a parameter reflecting the sensitivity of demand to own price. By summing across all firms in island (i) yields the aggregate demand in i. Note that uncertainty regarding other island prices do not affect demand for residents in island (i). However, uncertainty regarding the fundamentals (here $\mathrm{m}$ ) enters into the demand functions. Equating (1) and (2) yields the market clearing price in island $i$.

$$
\mathrm{p}_{\mathrm{i}}=(1-\mathrm{r}) \mathrm{E}_{\mathrm{i}}\left(\left(\mathrm{m} \mid \Omega_{\mathrm{i}}\right)\right)+\mathrm{rE}_{\mathrm{i}}\left(\left(\overline{\mathrm{p}} \mid \Omega_{\mathrm{i}}\right)\right)
$$

Where $r=\frac{b}{b+c}$. The market clearing price in each island (i) is the combination of expectations of fundamental variable and aggregate price level where the relative weight on the expectations determines by the slopes of aggregate demand and supply. This pricing rule is micro-founded and can be derived from a DSGE model (Angeletos and Lao, 2009). Unlike original formulation of Lucas island economy, it is assumed that the information set in island $\mathrm{i}\left(\Omega_{\mathrm{i}}\right)$ is different from the information set in other islands like $\mathrm{j}\left(\Omega_{\mathrm{j}}\right)$ and we allow islanders to have private information about monetary shocks. In this context, although fundamental variable (m), as in the original version of the island economy model, is a variable that the central bank has full control over and is known across agents in the islands, hence, it is a "common knowledge", there is also an idiosyncratic effect that originates from heterogeneity of information set between islands $\left(\Omega_{i} \neq \Omega_{j}\right)$ due to private information that is not common knowledge ${ }^{6}$.

Parameter $r$ between zero and unity governs the strategic interaction between islands. Agents in each island assign a positive weight on the expected fundamental variable $(\mathrm{m})$ and a weight equal to $r$ on the expected action of others, to arrive at the price in island $i$. If $r$ is large (close to 1 ) price decisions in island ( $i$ ) is dominated by anticipation of what others do, rather than what the fundamentals are. Equation (3) has the interpretation in the spirit of the beauty contest example mentioned in the Keynes' General theory (1936).

Based on equation (3), the price of goods for agents in island (i) is influenced by two sources of uncertainty: uncertainty about the expectation of the economywide price in island i given the information set available to the agents in island, and uncertainty about fundamental variable. In the simplest case, $\mathrm{m}$ is common knowledge, hence the equilibrium implies $\mathrm{p}_{\mathrm{i}}=\mathrm{m}$ for all $\mathrm{i}$. That is, under perfect information, individual rational actions individually are consistent with socially

6 Takashi Ui (2003) generalizes Lucas-island economy in this way to demonstrate that the real effects in this setting can also be affected by the public information due to imperfect common knowledge about fundamental variable (money supply). 
optimal actions. However, if we relax the perfect common knowledge assumption, what would be the effect of the degree of information precision regarding the fundamental variable on the profile of prices throughout islands? Does more precision on the fundamental variable imply that prices are more closely aligned to the money supply? This is where we can appreciate the signalling role of the central bank. To start, let us consider a case where the fundamental variable (m) is not common knowledge. ${ }^{?}$

Does greater information precision on money supply mean that the prices are tied closer to the fundamentals? ${ }^{8}$ We now examine the case where money supply is not common knowledge.

As it is shown in equation (3), price in island (i) depends on the realization of a fundamental state of the economy (money supply) which is unobserved. Fundamental variable has a prior distribution which is common knowledge. At the start of the play, nature picks a value for the money supply which the players cannot observe. There are two sorts of money supply signals: public and private.

Public signal is commonly observed by the residents in all islands. This signal can be taken to represent information gleaned from newspaper articles or other sources that report on central bank procedures. The public signal is given by:

$$
\mathrm{y}=\mathrm{m}+\varepsilon \quad ; \varepsilon \sim \mathrm{N}\left(0, \frac{1}{\mathrm{k}_{\mathrm{y}}}\right)
$$

Where $\varepsilon$ is distributed normally, independent of $\mathrm{m}$, with mean zero and standard deviation $\frac{1}{\mathrm{k}_{\mathrm{y}}}$. The fundamental variable $(\mathrm{m})$ is the true value of money supply and $\mathrm{y}$ is a noise-contaminated public signal for $\mathrm{m}-$ for instance, the monetary policy instrument. In addition to the public signal (y), residents of the island (i) observe the realization of a private signal:

$$
\mathrm{x}_{\mathrm{i}}=\mathrm{m}+\mathrm{v}_{\mathrm{i}} \quad ; v_{\mathrm{i}} \sim \mathrm{N}\left(0, \frac{1}{\mathrm{k}_{\mathrm{x}}}\right)
$$

Noise $\left(v_{\mathrm{i}}\right)$ associated with the private signal $\left(\mathrm{x}_{\mathrm{i}}\right)$ are distributed normally with mean zero and standard deviation $\frac{1}{\mathrm{k}_{\mathrm{x}}}$, and is independent of $\mathrm{m}$ and $\varepsilon$, hence $\mathrm{E}\left(v_{\mathrm{i}} v_{\mathrm{j}}\right)=0$ for $\mathrm{i} \neq \mathrm{j}$. The private signal can be taken to represent any information

\footnotetext{
The arguments follow Amato, Morris and Shin (2002a), Morris and Shin (2002b).

8 Phelps (1983) posed this question in the context of an economy in which the central bank is determined to combat the inflation expectation of the private sector agents, and noted that the answer depends on the interaction of beliefs between agents.
} 
that each island has observed but is not common knowledge, such as news received through private discussions. This is the sense in which these signals are private. $^{9}$

The information set available to residents of the island (i) is limited to observation on the pair $\left(\mathrm{y}, \mathrm{x}_{\mathrm{i}}\right)$. Residents of each island form posteriors about the money supply and the signals received by other islands on the above information set. The $\mathrm{k}_{\mathrm{x}}$ represents the precision of the private signal and $\mathrm{k}_{\mathrm{y}}$ denotes the precision of the public information. The expected value of $\mathrm{m}$ based on both private and public information available in island (i) can be calculated by Bayes updating rule as:

$$
\mathrm{E}_{\mathrm{i}}\left(\mathrm{m} \mid \mathrm{x}_{\mathrm{i}}, \mathrm{y}\right)=\frac{\mathrm{k}_{\mathrm{x}}}{\mathrm{k}_{\mathrm{x}}+\mathrm{k}_{\mathrm{y}}} \mathrm{x}_{\mathrm{i}}+\frac{\mathrm{k}_{\mathrm{y}}}{\mathrm{k}_{\mathrm{x}}+\mathrm{k}_{\mathrm{y}}} \mathrm{y}
$$

$\frac{\mathrm{k}_{\mathrm{x}}}{\mathrm{k}_{\mathrm{x}}+\mathrm{k}_{\mathrm{y}}}$ and $\frac{\mathrm{k}_{\mathrm{y}}}{\mathrm{k}_{\mathrm{x}}+\mathrm{k}_{\mathrm{y}}}$ are precision weights of private and public signal, respectively. The variance of this expectation can be calculated by combining the variances of the two stochastic error terms of public and private signals:

$$
\operatorname{Var}\left(\mathrm{m} \mid \mathrm{x}_{\mathrm{i}}, \mathrm{y}\right)=\frac{1}{\mathrm{k}_{\mathrm{x}}+\mathrm{k}_{\mathrm{y}}}
$$

Substituting equation (6) in equation (3) and solving the difference equation with the method of undetermined coefficients, the price in island (i) will be:

$$
\mathrm{p}_{\mathrm{i}}=\frac{(1-\mathrm{r}) \mathrm{k}_{\mathrm{x}}}{(1-\mathrm{r}) \mathrm{k}_{\mathrm{x}}+\mathrm{k}_{\mathrm{y}}} \mathrm{x}_{\mathrm{i}}+\frac{\mathrm{k}_{\mathrm{y}}}{(1-\mathrm{r}) \mathrm{k}_{\mathrm{x}}+\mathrm{k}_{\mathrm{y}}} \mathrm{y}
$$

Note that when $r=0$, the best response is given by $p_{i}=E_{i}\left(m \mid x_{i}, y\right)$, hence an agent's action is based on his own expectation. In this case, the weight of each signal, public and private, corresponds to their relative precision. But when there is strategic complementarity ( $\mathrm{r} \# 0)$, agents put less weight on their own (private) signal relative to the case where there is no strategic interaction $(\mathrm{r}=0)$, and put more weight on the public signal ${ }^{10}$. In this case, the aggregate price in the economy is given by:

9 The assumption that each member of the public receives a noisy private signal regarding the fundamental variables is used in the literature on global games which attempts to model situations of imperfect common knowledge. See Morris and Shin (2001). See also Jalali-Naini and Naderian (2014).

${ }^{10}$ Consider the case in which precision of both signals are the same. The weight of private signal is $\frac{1-r}{2-r}$ and weight of public signal: $\frac{1}{2-r}$. With the presence of strategic complementarity, public signal weight is more than private signal. But, in the absence of strategic interaction the weight of public and private signals are both equal $\left(\frac{1}{2}\right)$. 


$$
\overline{\mathrm{p}}=\mathrm{m}+\frac{\mathrm{k}_{\mathrm{y}}}{(1-\mathrm{r}) \mathrm{k}_{\mathrm{x}}+\mathrm{k}_{\mathrm{y}}} \varepsilon
$$

As can be seen, that coefficient on $\varepsilon$ is increasing in $r$. Therefore, the presence of strategic complementarity amplifies the impact of the noise associated with public signal $(\varepsilon)$ on the aggregate price (outcome).

MS (2002) extend this argument to an asset pricing model where the price of an asset today is the average of islanders' expectation of tomorrow's price. From (3), we can get the best response of the residents in island (i) as in (10):

$$
p_{i}=(1-r) E_{i}(m)+r E_{i}\left(\int p_{j} d j\right)
$$

Substituting for $\mathrm{p}_{\mathrm{j}}$ in (10) and iterating the equation forward, equation (11) can be obtained.

$$
\begin{aligned}
\mathrm{p}_{\mathrm{i}}=(1-\mathrm{r}) \mathrm{E}_{\mathrm{i}}(\mathrm{m})+ & (1-\mathrm{r}) r \mathrm{E}_{\mathrm{i}}(\overline{\mathrm{E}}(\mathrm{m}))+(1-\mathrm{r}) \mathrm{r}^{2} \mathrm{E}_{\mathrm{i}}\left(\overline{\mathrm{E}}^{2}(\mathrm{~m})\right)+\cdots \\
& =(1-\mathrm{r}) \sum_{\mathrm{k}=0}^{\infty} \mathrm{r}^{\mathrm{k}} \mathrm{E}_{\mathrm{i}}\left(\overline{\mathrm{E}}^{\mathrm{k}}(\mathrm{m})\right)
\end{aligned}
$$

$\bar{E}(\mathrm{~m})$ Stands for the average expectation operator as given by (12).

$$
\bar{E}(m)=\int E_{j}[.] d j
$$

Equation (11) yields the optimal price in each island which is a geometric sum of higher order beliefs about money supply. Note that the greater the strategic complementarity, the greater the weight placed on higher-order beliefs about $\mathrm{m}$. In order to determine the expression for $p_{i}$ in (11) we must solve for $E_{i}\left(\bar{E}^{k}(m)\right)$. Recall from (6) that that the expected price of money supply for residents in the island (i) is:

$$
\mathrm{E}_{\mathrm{i}}\left(\mathrm{m} \mid \mathrm{x}_{\mathrm{i}}, \mathrm{y}\right)=\frac{\mathrm{k}_{\mathrm{x}}}{\mathrm{k}_{\mathrm{x}}+\mathrm{k}_{\mathrm{y}}} \mathrm{x}_{\mathrm{i}}+\frac{\mathrm{k}_{\mathrm{y}}}{\mathrm{k}_{\mathrm{x}}+\mathrm{k}_{\mathrm{y}}} \mathrm{y}
$$

Integration (6.1) across islands, the average expectation for money supply can be obtained as:

$$
\bar{E}(m)=\int E_{j}\left[\left(m \mid x_{j}, y\right)\right] d j=\frac{k_{x}}{k_{x}+k_{y}} m+\frac{k_{y}}{k_{x}+k_{y}} y
$$

Now, the expectation of residents in the island (i) of the average expectation of money supply $\overline{\mathrm{E}}(\mathrm{m})$ in other islands is: 


$$
E_{i}\left(\left(\bar{E}(m) \mid x_{i}, y\right)\right)=\frac{\left(\left(k_{x}+k_{y}\right)^{2}-k_{x}^{2}\right)}{\left(k_{x}+k_{y}\right)^{2}} y+\frac{k_{x}{ }^{2}}{\left(k_{x}+k_{y}\right)^{2}} x_{i}
$$

From (14), we can surmise that, the average expectation operator does not satisfy the law of iterated expectation when there is asymmetric information, i.e. information across agents are not homogeneous because of differences in their information set due to different private signals. That is to say, the average expectation of the islander $i$ for the average expectation of money supply is not the same as the average expectation of money supply. This is because of the stipulation that expectation of residents in the island (i) regarding the expectation of the islander (j)'s expectation about money supply partially depends on his private signal--and crucially does not solely depends on a common signal, private or public.

$$
E_{i}\left(E_{j}(m) \mid x_{i}, y\right)=E_{i}\left(m \mid x_{i}, y\right)+\frac{k_{x} k_{y}}{\left(k_{x}+k_{y}\right)^{2}}\left(y-x_{i}\right)
$$

So longs as public signals for islander i deviates from her private signal - that is, $\left(\mathrm{y}-\mathrm{x}_{\mathrm{i}}\right)$ is non-zero, the law of iterated expectation does not apply. For instance, if the islander (i) observes a low public signal about money supply (say a low y; 100) and a high private signal regarding the same variable $m$ (say $x_{i} 200$ ), she forms an average expectation of $\mathrm{m}$ based on their relative precision weights $\left(\frac{\mathrm{k}_{\mathrm{x}}}{\mathrm{k}_{\mathrm{x}}+\mathrm{k}_{\mathrm{y}}}\right.$, $\left.\frac{\mathrm{k}_{\mathrm{y}}}{\mathrm{k}_{\mathrm{x}}+\mathrm{k}_{\mathrm{y}}}\right)$, however, islander (i) expect islander (j) to have a lower expectation for $\mathrm{m}$ compared to his own expectation, because the second term on the right-handside is negative (200-100). The converse also stands. ${ }^{11}$

Higher order expectation (average of average expectation of average expectation of $\mathrm{m}$ ) as in (14) puts more weight on the (noisy) public information, that is, the value of $y$ becomes more weighty and the second term on the RHS becomes less significant weights (hence the precision weight of the actual $\mathrm{m}$ ) for formation of $\overline{\mathrm{E}}^{\mathrm{k}}(\mathrm{m})$. For instance when $\mathrm{k}$ tends to infinity, the weight of $\mathrm{m}$ tends towards zero, and the coefficient of $y$ tends towards unity - that is, the kth order belief of $\mathrm{m}$, $\overline{\mathrm{E}}^{\mathrm{k}}(\mathrm{m})$, equals public signal. By induction we have:

$$
\overline{\mathrm{E}}^{\mathrm{k}}(\mathrm{m})=\left(1-\left(\frac{\mathrm{k}_{\mathrm{x}}}{\mathrm{k}_{\mathrm{x}}+\mathrm{k}_{\mathrm{y}}}\right)^{\mathrm{k}}\right) \mathrm{y}+\left(\frac{\mathrm{k}_{\mathrm{x}}}{\mathrm{k}_{\mathrm{x}}+\mathrm{k}_{\mathrm{y}}}\right)^{\mathrm{k}} \mathrm{m}
$$

${ }^{11}$ If an islander (i) observes a high public signal (200) and a low private signal (100) on money supply with the same relative precision weights, she forms identical expectation on $\mathrm{m}$; however, the islander (i) expects the islander (j) to have a higher expectation of $\mathrm{m}$ than for him. 
Note that, since $y=m+\varepsilon$ higher order beliefs are more sensitive to the noise in the public signal than lower orders. Substituting (16) in equation (11) we obtain:

$$
\mathrm{p}_{\mathrm{i}}=\frac{(1-\mathrm{r}) \mathrm{k}_{\mathrm{x}}}{(1-\mathrm{r}) \mathrm{k}_{\mathrm{x}}+\mathrm{k}_{\mathrm{y}}} \mathrm{x}_{\mathrm{i}}+\frac{\mathrm{k}_{\mathrm{y}}}{(1-\mathrm{r}) \mathrm{k}_{\mathrm{x}}+\mathrm{k}_{\mathrm{y}}} \mathrm{y}
$$

which is exactly the equation (8) we found before. This explicit solution allows us to address the important question of how the precision of public disclosures of central banks regarding the variable of interest $(\mathrm{m})$ can affect welfare. Is the welfare always improving with the increase in the precision of public signal about money supply? We answer this question through an explicit policy loss function as in MS (2002).

\section{Welfare Implications of Overreactions:}

Given our previous discussions regarding the possibility of overreaction to public signals, we continue to assess welfare implications of overreactions based on the beauty contest model discussed in the first section, under perfect information, like Lucas islands $m=p_{i}$. The question is in what ways precision of public information matters for alignments between prices and money supply (fundamental variable) $)^{12}$. We can specify a loss function following MS (2002) by defining a unit integral of the difference between $\mathrm{p}_{\mathrm{i}} \mathrm{s}$ across islands and the money supply as in (17):

$$
L=\int_{0}^{1}\left(p_{i}-m\right)^{2} d i
$$

To minimize social loss, the central bank attempts to minimize the distance between the decision of agents (i) regarding price in each island $\left(\mathrm{p}_{\mathrm{i}}\right)$ and $\mathrm{m}$. When uncertainty is absent regarding $\mathrm{m}$, prices are identical across all islands and equal to $\mathrm{m}$ and there is no loss. However, in the presence of uncertainty regarding the fundamental, L measures the social loss and can be reduced by the ability of islanders to better approximate $\mathrm{m}$. Note that the loss in welfare does not only emanate from coordination by itself but rather from information spillovers created by second guessing decisions of other agents throughout the islands. Such external effect on prices is socially inefficient because, as assumed by MS (2000), it is zerosum hence gain by winners are compensated by the loss of the losers. The rate of

\footnotetext{
${ }^{12}$ In a simple equilibrium setting only relative prices have implications for resource allocation. However, in an incomplete information setting where monetary policy actions work through market expectations, price levels transmit information regarding future financial conditions, therefore, their tightness with the fundamentals matters. Morris and Shin (2002).
} 
externality on price decision can be measured by the strategic complementarities parameter $r$ (as it appears in equation 3$)^{13}$.

For computing the loss function, let us assume that islander (i) know for certain behaviour of other islanders and they all observe announcement on $\mathrm{m}$ by the central bank as common knowledge ${ }^{14}$, however, they are uncertain regarding the fundamental $(\mathrm{m})$ signalled by the central. Note that since in this case there is no private signal, we focus on public information and errors associated with it. Thus, in this case posteriors via the Bayes updating rule can be derived as:

$$
(\mathrm{m} \mid \mathrm{y}) \sim \mathbb{N}\left(\mathrm{y}, \frac{1}{\mathrm{k}_{\mathrm{y}}}\right)
$$

By, symmetry, the unique equilibrium is given by:

$$
\mathrm{p}_{\mathrm{i}}=\overline{\mathrm{p}}=\mathrm{E}(\mathrm{m} \mid \mathrm{y})=\mathrm{y}
$$

Expected loss conditional on $\mathrm{m}$ is thus given by:

$$
\mathrm{E}(\mathrm{m} \mid \mathrm{y})=\mathrm{E} \int_{0}^{1}\left(\mathrm{p}_{\mathrm{i}}-\mathrm{m}\right)^{2} \mathrm{di}=\mathrm{E}(\mathrm{y}-\mathrm{m})^{2}=\frac{1}{\mathrm{k}_{\mathrm{y}}}
$$

Therefore, based on (20), social loss is decreasing in the precision of public signal $\left(\mathrm{k}_{\mathrm{y}}\right)$. We now compare this result with the more general case in which residents in each island have private information $\left(\mathrm{x}_{\mathrm{i}}\right)$ in addition to public information (y). From previous discussions we know that with private and public signal, the unique equilibrium is given by equation (8). We can rewrite the equilibrium price in (8) as:

$$
\mathrm{p}_{\mathrm{i}}=\mathrm{m}+\frac{(1-\mathrm{r}) \mathrm{k}_{\mathrm{x}}}{(1-\mathrm{r}) \mathrm{k}_{\mathrm{x}}+\mathrm{k}_{\mathrm{y}}} \mathrm{v}_{\mathrm{i}}+\frac{\mathrm{k}_{\mathrm{y}}}{(1-\mathrm{r}) \mathrm{k}_{\mathrm{x}}+\mathrm{k}_{\mathrm{y}}} \varepsilon
$$

If $r=0$ in equation (21), the two types of noises, private and public, would be given weights in price determination proportionate to their respective precision as in (22):

${ }^{13}$ Note that, the zero sum nature of coordination element is questioned by Woodford (2005), Angeletos and Pavan (2004) and Hellwig (2004). They believe that coordination itself has some social value, and by adding the value of coordination to social welfare function in Morris and Shin (2002) more public information precision will always be welfare improving.

${ }^{14}$ That is, they all have observed announcement on $\mathrm{m}$, they all know that others have also observed the announcement, and they all have the same understanding regarding the announcement. 


$$
\mathrm{p}_{\mathrm{i}}=\mathrm{m}+\frac{\mathrm{k}_{\mathrm{x}}}{\mathrm{k}_{\mathrm{x}}+\mathrm{k}_{\mathrm{y}}} v_{\mathrm{i}}+\frac{\mathrm{k}_{\mathrm{y}}}{\mathrm{k}_{\mathrm{x}}+\mathrm{k}_{\mathrm{y}}} \varepsilon
$$

Since $r=0$, equation (22) represents a case where there is no spillover effect coming from coordination role of the central bank announcement (public signal). In the presence of strategic complementarity (22) is not valid because the public signal gets a larger weight (i.e. overreaction to public signal) its noise also finds a relatively larger weight as in (21). What is the effect of the above overreaction to public signal on the loss function? The expected social loss, given $\mathrm{m}$, is obtained squaring the difference between $\mathrm{m}$ and $\mathrm{p}_{\mathrm{i}}$ in (21) is shown by (23)

$$
E(L \mid m)=\frac{(1-r)^{2} k_{x}+k_{y}}{\left((1-r) k_{x}+k_{y}\right)^{2}}
$$

From (23) we can find the effect of increased precision of private signal on expected social loss. This can be done by taking the derivative of the expected loss with respect to $\mathrm{k}_{\mathrm{x}}$.

$$
\frac{\partial \mathrm{E}(\mathrm{L} \mid \mathrm{m})}{\partial \mathrm{k}_{\mathrm{x}}}=(\mathrm{r}-1)\left(\frac{(1+\mathrm{r}) \mathrm{k}_{\mathrm{y}}+(1-\mathrm{r})^{2} \mathrm{k}_{\mathrm{x}}}{\left(\mathrm{k}_{\mathrm{y}}+(1-\mathrm{r}) \mathrm{k}_{\mathrm{x}}\right)^{3}}<0\right.
$$

From (24) it is clear that social loss is decreasing with respect to private signal precision. However, if we take the derivative of social loss with respect to public signal precision, we get a different conclusion regarding the impact of public signal precision.

$$
\frac{\partial \mathrm{E}(\mathrm{L} \mid \mathrm{m})}{\partial \mathrm{k}_{\mathrm{y}}}=\frac{-\mathrm{k}_{\mathrm{y}}+(1-\mathrm{r})(2 \mathrm{r}-1) \mathrm{k}_{\mathrm{x}}}{\left(\mathrm{k}_{\mathrm{y}}+(1-\mathrm{r}) \mathrm{k}_{\mathrm{x}}\right)^{3}}
$$

For determining the sign of (25) we observe the following

$$
\frac{\partial \mathrm{E}(\mathrm{L} \mid \mathrm{m})}{\partial \mathrm{k}_{\mathrm{y}}}<0 \quad \text { iff } \quad \frac{\mathrm{k}_{\mathrm{x}}}{\mathrm{k}_{\mathrm{y}}}<\frac{1}{(1-\mathrm{r})(2 \mathrm{r}-1)}
$$

If $r>0.5$, there exists a range of values for parameter $k_{x}$ and $k_{y}$ whereby more precision of public information results in large social loss. MS (2000) found that $\mathrm{k}_{\mathrm{x}}$ must be sufficiently low, that is, private signal is not very precise, so that higher precision of public information is to be welfare improving. 
Figure 1: Social loss contours across islands

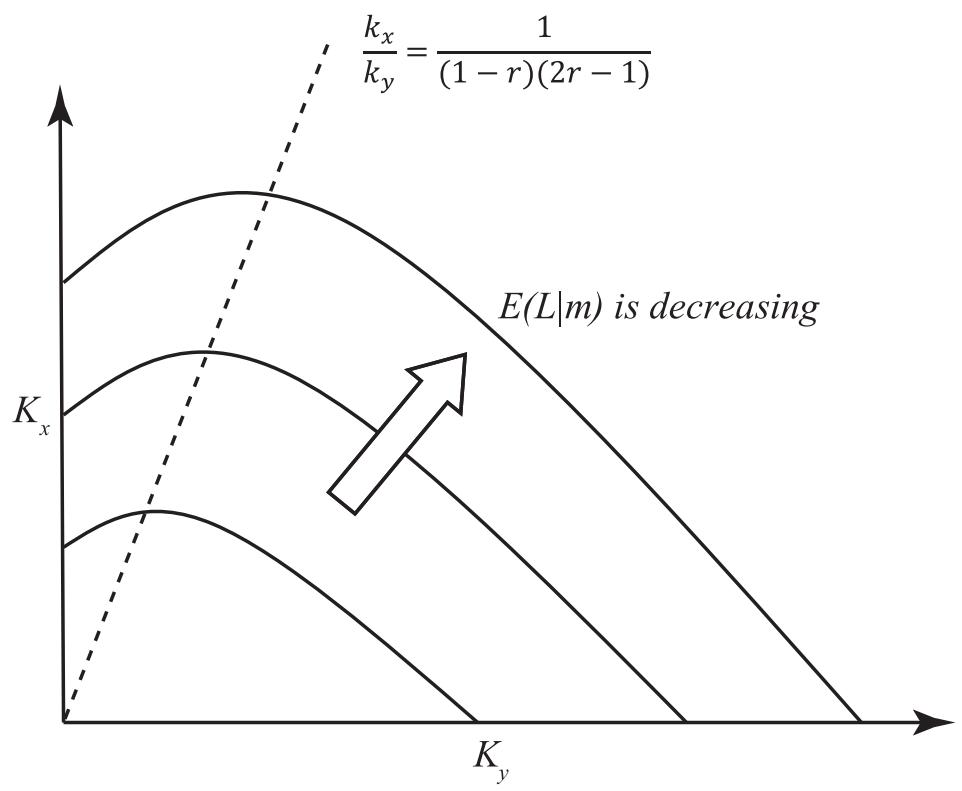

Figure 1 shows that each curve is the locus of the pairs of $\mathrm{k}_{\mathrm{x}}$ and $\mathrm{k}_{\mathrm{y}}$ that correspond to the same level of social loss across islands (1). The curves or the contours show pairs of $\left(k_{x}, k_{y}\right)$ that satisfy $\frac{(1-r)^{2} k_{x}+k_{y}}{\left((1-r) k_{x}+k_{y}\right)^{2}}=$ constant, for $r$ greater than 0.5. The interpretation is that when the parameter of strategic complementary is high, $r>0.5$, i.e. "coordination motive" is high hence individuals put more weight on the public signal or information (rather than private signal or fundamentals) to decide on their own action. If public information is not accurate, the above behaviour results in overreaction to public announcements. This behaviour is welfare reducing since there is a wedge between the actual equilibrium and the fundamental equilibrium. Increasing the precision of public information helps agents coordinate their true actions, but they coordinate at the expense of choosing actions that are further away from the true money supply (m). The impact of the error in the public signal is amplified, leading to excess volatility. Since the planner wants agents to be as close to the fundamental as possible, he finds this overreaction to public noise or excess volatility socially costly.

In case where $r<0.5$, i.e. "coordination motive" is not high, the same quality of public information (as in the above case) is welfare improving. This is due to the first order effect that more accurate information implies that prices will be closer to money supply (fundamentals). On the other hand, when agents have a strong 
desire to coordinate $(r>0.5)$, agents place more weight on public signal relative to private signal when choosing their equilibrium prices.

\section{Drawbacks of MS model}

Svensson (2005) makes two observations regarding the base-line MS model (2002). Firstly, the result that welfare is locally decreasing in the precision of public information holds only with restriction on information parameters that are empirically very restrictive. Secondly, when precision of the public signal is not less than that for the private information, availability of the public information results in higher welfare than in a case when the public signal is absent. In other words, the expression $f(r)=(1-r)(2 r-1)$ in (26) reaches a maximum of $\mathrm{f}(\mathrm{r}) \leq \mathrm{f}\left(\frac{3}{4}\right)=\frac{1}{8}$ when $\mathrm{r}=\frac{3}{4}$. If "coordination motive" is high $(\mathrm{r}>0.5)$, condition (26) is violated if $\frac{\mathrm{k}_{\mathrm{x}}}{\mathrm{k}_{\mathrm{y}}}<8$ In other words, private signal precision must be 8 times higher than that for public signal to allow for overreaction by individuals. However, in line with their delegated mandates, central banks have invested large resources for gathering, processing, and scrutinizing economic data, including receiving and purchasing of data from private entities thus have better access to economy-wide public and private information than any single private individual or company (Romer and Romer 2000).

In reaction to Svensson (2005), Baeriswyl (2011) questioned the specification of the social welfare function in MS (2002). ${ }^{15}$ In particular, the zero-sum nature of the "coordination element" is a specific case of a more general social welfare function in which the negative effect of public signal transparency due to economic distortion (stabilization) is completely compensated by dispersion (coordination) at the social level. Baeriswyl (2011) introduces a non-zero sum social welfare and assumes that both the dispersion of prices $^{16}$ across islands $\int_{0}^{1}\left(p_{i}-\bar{p}\right)^{2}$ di and the distortion of the average prices from money supply $(m-\bar{p})^{2}$ will reduce the social level of welfare. Therefore, the social loss function is:

\footnotetext{
${ }^{15}$ On this Also see Woodford (2005) and Hellwig (2004).

${ }^{16}$ When there are different prices for the same good in the economy called price dispersion, agents buy more of the relatively cheaper goods and less of the relatively more expensive goods. Because of diminishing marginal utility, the increase in utility derived from consuming more of some goods is less than the loss in utility due to consuming less of the more expensive goods. Hence, price dispersion reduces utility. This dynamic mark-up distortion originates from sticky prices and staggered price setting in canonical form of new Keynesian economics (Walsh (2010).
} 


$$
L(p, m)=\int_{0}^{1}\left(p_{i}-\bar{p}\right)^{2} d i+\lambda(m-\bar{p})^{2}
$$

where $\mathrm{p}$ is the profile of prices among all islands and the parameter $\lambda$ depicts the weight of economic distortion emanating from money supply (fundamental variable). The social loss shown in equation (27) may explain different specifications including the loss incurred by the representative household--derived from a micro-founded monopolistically competitive economy. The welfare in MS is a special case that corresponds to the loss in (27) where $\lambda=1$ (Baeriswyl 2011). Considering equation (22), the expected social loss can be calculated as:

$$
E(L \mid m)=\frac{(1-r)^{2} k_{x}+\lambda k_{y}}{\left((1-r) k_{x}+k_{y}\right)^{2}}
$$

If the derivative of expected loss with respect to public signal precision $\mathrm{k}_{\mathrm{y}}$ is taken, the following relationship is obtained:

Hence,

$$
\frac{\partial \mathrm{E}(\mathrm{L} \mid \mathrm{m})}{\partial \mathrm{k}_{\mathrm{y}}}=\frac{-\lambda \mathrm{k}_{\mathrm{y}}+(1-\mathrm{r})(\lambda-2(1-\mathrm{r})) \mathrm{k}_{\mathrm{x}}}{\left(\mathrm{k}_{\mathrm{y}}+(1-\mathrm{r}) \mathrm{k}_{\mathrm{x}}\right)^{3}}
$$

$$
\frac{\partial \mathrm{E}(\mathrm{L} \mid \mathrm{m})}{\partial \mathrm{k}_{\mathrm{y}}}<0 \quad \text { iff } \quad \frac{\mathrm{k}_{\mathrm{x}}}{\mathrm{k}_{\mathrm{y}}}<\frac{1}{\lambda(1-\mathrm{r})(\lambda-2(1-\mathrm{r}))}
$$

The expression $\lambda(1-r)(\lambda-2(1-r))$ in the denominator of equation (30) and reaches its maximum where the value of strategic complementarity parameter $(r)$ equals $\mathrm{r}=1-\frac{\lambda}{4}$ which corresponds to $\frac{\mathrm{k}_{\mathrm{x}}}{\mathrm{k}_{\mathrm{y}}}<\frac{\lambda^{3}}{8}$. This result shows that if the social value of coordination is smaller than in MS $(\lambda>1)$, Svensson's (2006) argument pertaining to unrealistic conditions for detrimental effect of transparency is invalid. In this case, lower transparency may be optimal even when the accuracy of public signal is higher than the private one. For example, suppose the case where $\lambda=2$, the maximum value of $\frac{\mathrm{k}_{\mathrm{x}}}{\mathrm{k}_{\mathrm{y}}}$ considering equation (30) equals unity for $=\frac{1}{2}$. This result shows that the overreaction effect of full-transparency may emerge even where the accuracy of both private and public signals are the same.

\section{Strategies to Limit Overreaction}

Considering the above results, it can be inferred that the issue of communication strategy of the central bank goes beyond the question of whether disclosing 
information is desirable or not: it also deals with the question of how to disclose the information in such a way that the market does not excessively overreact to it. Controlling the degree of market participant 's overreaction to its disclosure is an important and challenging task for a central bank. This can be performed by two proposed communication strategies: partial publicity and partial transparency. These two strategies will be explained in the next section.

\subsection{Partial Publicity (PP)}

In the framework proposed by $\mathrm{CH}$ (2008), each islander (i) obtains a private signal $x_{i}$ and only a subgroup of islanders (informed islanders) receive semi-public signal y. Uninformed islanders receive private signal but the informed ones receive both private signal and have access to public signal. The signals diverge from the fundamental $m$ by normally distributed error terms. The difference between PP framework and MS (2002) is the proportion (P) of islanders that have access to semi-public (common) signal y. $\mathrm{Q}$ is the degree of publicity. Optimal average price is derived separately for uninformed islanders (1-Q) and informed islanders (Q). Since these islanders have no idiosyncratic information (common knowledge) regarding $\mathrm{m}$, the optimal price for uninformed islanders is only based on their private signal:

$$
P_{i, 1-Q}=x_{i}
$$

The informed islanders not only have private signal but also have access to semipublic signal, and the optimal price for this group, following (MS 2002), is a linear combination of the two signals.

$$
P_{i, Q}=\frac{(1-r Q) k_{y}}{k_{x}+k_{y}(1-r Q)} x_{i}+\frac{k_{x}}{k_{x}+k_{y}(1-r Q)} y
$$

Notice that in equation (32) public signal weight for informed agents is smaller than MS (2002) since Q is lower than one. In this framework, the informed group knows that there are islanders that have no access to public signal, therefore they reduce the weight of public signal in $\left(\frac{k_{x}}{k_{x}+k_{y}(1-r Q)}\right.$ derivation of the optimal
price.

Overall average price (for informed and uninformed islander), the optimal price, is derived as:

$$
\bar{P}=\frac{(1-Q) k_{x}+(1-r Q) k_{y}}{k_{x}+k_{y}(1-r Q)} \bar{x}+\frac{Q k_{x}}{k_{x}+k_{y}(1-r Q)} y
$$


As one would expect, the weight of public signal in the aggregate price is lower than when $Q=1$, that is MS (2002). For this reason, overreaction to public signals will be limited compared to complete publicity--availability of public signal to all, $\mathrm{Q}=1$.

\subsection{Partial Transparency}

In this case we assume that $\mathrm{CB}$ practices partial transparency and its public signal sent to all islanders with an idiosyncratic noise, thereby reducing the degree of common knowledge. This approach essentially makes CB disclosures more ambiguous. Ambiguity of the public signal is defined as in (34):

$$
y_{i}=m+\varepsilon+\phi_{i} \quad ; \varepsilon \sim N\left(0, \frac{1}{k_{y}}\right) ; \phi_{i} \sim N\left(0, \frac{1}{k_{\phi}}\right)
$$

This public signal $\left(y_{i}\right)$ is now semi-public with subscript (i), since it contains a specific private error term $\left(\phi_{i}\right)$ in addition to the common error term $(\varepsilon)$ that exists in the previous frameworks.

Using the Bayesian updating rule, we can compute islanders' expectation about money supply and average public signal $(\bar{y})$ conditional on information sets in each island:

$$
\begin{aligned}
& E_{i}\left(m \mid x_{i}, y_{i}\right)=\frac{k_{x}+k_{\phi}}{k_{x}+k_{\phi}+k_{y}} x_{i}+\frac{k_{y}}{k_{x}+k_{\phi}+k_{y}} y_{i} \\
& E_{i}\left(\bar{y} \mid x_{i}, y_{i}\right)=\frac{k_{\phi}}{k_{x}+k_{\phi}+k_{y}} x_{i}+\frac{k_{x}+k_{y}}{k_{x}+k_{\phi}+k_{y}} y_{i}
\end{aligned}
$$

Weighted average of islanders' private and public signals determines the best estimate of money supply in this structure. The weights in relationships (35) and (36) reflect relative accuracy of each signal. Linear combination of private and public signals is the optimal price in each island (i), as shown by (37).

$$
\begin{aligned}
& P_{i}=\frac{\left((1-r) k_{\phi}+k_{x}\right) k_{y}}{k_{x} k_{\phi}+k_{\phi} k_{y}(1-r)+k_{x} k_{y}} x_{i}+ \\
& \frac{k_{x} k_{\phi}}{k_{x} k_{\phi}+k_{\phi} k_{y}(1-r)+k_{x} k_{y}} y_{i}
\end{aligned}
$$

Then, overall price will be given by: 


$$
\begin{aligned}
& E_{i}(\bar{P})=\frac{\left((1-r) k_{\phi}+k_{x}\right) k_{y}}{k_{x} k_{\phi}+k_{\phi} k_{y}(1-r)+k_{x} k_{y}} \bar{x}+ \\
& \frac{k_{x} k_{\phi}}{k_{x} k_{\phi}+k_{\phi} k_{y}(1-r)+k_{x} k_{y}} \bar{y}
\end{aligned}
$$

Like in the case of PP, the weight assigned to the public signal in equation (38) is smaller than that in MS (2002) model. Moreover, public signal weight in (38) is a decreasing function of precision (private error) of semi-public signal $\left(k_{\phi}\right)$. This shows that disclosing the public signal with an idiosyncratic noise to each agent reduces the degree of common knowledge and hence the overreaction to the public signal.

\section{Conclusion}

A pillar of inflation targeting framework has been full transparency. Recent experience shows that financial markets in both advanced economies and emerging market economies overreact to $\mathrm{CB}$ policy signals when those signals are contaminated. Literature on the information dispersion and imperfect common knowledge developed over the past fifteen years argues that widespread public information by CB is not always a superior strategy since it may entail detrimental effect on social welfare through market overreaction to inevitable inaccuracies contained in contaminated CB policy signals.

Policy conclusions that can be inferred from the discussions in this paper are: (a)-when central bank announcements are common knowledge and information is abundant, the optimal communication policy is complete transparency; (b)however, in the more realistic situation where there is imperfect common knowledge in combination with strategic complementarity between players' actions, the optimal communication policy is incomplete transparency or a degree of opacity. When private information has low signals and public signals are contaminated with inaccuracies, central bank transparency can have harmful consequences due to overreaction to public signals. In other words, inevitable error of central bank in terms of data collection, economic variables prediction and other sources of measurement errors pass on through announcements to public and provide a wedge between fundamental based equilibrium and the expectationbased sunspot equilibrium. In such a setting, tackling the overreaction problem entails reducing the degree of common knowledge about public information. 
Policy conclusion (b) was obtained, following MS (2002), by incorporating imperfect common knowledge and strategic complementary into Lucas-Phelps island economy to highlight the dual role of information dissemination and coordination played by $\mathrm{CB}$ announcements. In this setting, public announcements by the central bank as a common knowledge not only convey information on the underlying fundamentals, but also may play a signalling role for coordination amongst economic agents trying to approximate common knowledge. If the central bank has the signalling instrument to influence outcomes, potential misallocations may result when economic agents put stronger than optimal reliance on imperfect public signals. In this situation, expectations will coordinate actions away from fundamentals leading to economic inefficiency exacerbation. This conclusion undermines the case for full transparency and underscores the negative effect of CB communication policy on market efficiency.

c-The widely acknowledged result concerning the focal role of CB announcements and the possibility that contaminated signals can result in distortive overreactions, the binary approach (full transparency vs. full opacity) to communication strategy changed the relevant policy question from (a) and (b) to the issue of the optimal degree of disclosure of public signals in order to reduce excessive overreactions. Disclosing transparent public information to a specified group of market participants (partial publicity) and disclosing ambiguous public information to all market participants (partial transparency) are two disclosure strategies discussed in this paper. 


\section{References:}

1. Angeletos, G. M., \& La'O, J. (2010). Noisy business cycles. In NBER Macroeconomics Annual 2009, Volume 24 (pp. 319-378). University of Chicago Press.

2. Angeletos, G. M., and Pavan, A. (2004). Transparency of information and coordination in economies with investment complementarities (No. w10391). National Bureau of Economic Research.

3. Amato, J. D., Morris, S., and Shin, H. S. (2002). Communication and monetary policy. Oxford Review of Economic Policy, 18(4), 495-503.

4. Arora, V., Arvanitis, T., Faruqee, H., N'Diaye, P., \& Griffoli, T. M. (2014). Emerging market volatility: Lessons from the taper tantrum (No. 14/9). International Monetary Fund.

5. Baeriswyl, R. (2011). Endogenous central bank information and the optimal degree of transparency. International Journal of Central Banking, 7(2), 85-111.

6. Baeriswyl, R., and Cornand, C. (2011). Transparency and monetary policy effectiveness. Annals of Economics and Statistics/Annales d'Économie et de Statistique, 175-194.

7. Cooper, R. (1999). Coordination games. Cambridge University Press.

8. Cornand, C., \& Heinemann, F. (2008). Optimal degree of public information dissemination. The Economic Journal, 118(528), 718-742.

9. Hayek, F. A. (1945). The use of knowledge in society. The American economic review, 519-530.

10. Heinemann, F., \& Illing, G. (2002). Speculative attacks: unique equilibrium and transparency. Journal of International Economics, 58(2), 429-450.

11. Hellwig, C. (2004). Heterogeneous information and the benefits of public information disclosures (october 2005) (No. 283). UCLA Department of Economics.

12. Jalali-Naini, Ahmad Reza, Mohammad Amin Naderain (2014), "Social Value of Information and Optimal Communication Policy of Central Banks." Journal of Money and Economy, Vol. 9, No.3.

13. Lucas, R. E. (1972). Expectations and the Neutrality of Money. Journal of economic theory, 4(2), 103-124.

14. Lucas, R. E. (1973). Some international evidence on output-inflation tradeoffs. The American Economic Review, 326-334.

15. Morris, S., \& Shin, H. S. (2002). Social value of public information. The American Economic Review, 92(5), 1521-1534. 
16. Morris, S., Shin, H. S., \& Tong, H. (2006). Social value of public information: Morris and Shin (2002) is actually pro-transparency, not con: Reply. The American Economic Review, 453-455.

17. Morris, S., \& Shin, H. S. (2007). Optimal communication. Journal of the European Economic Association, 5(2-3), 594-602.

18. Morris, S., \& Shin, H. S. (2001). Rethinking multiple equilibria in macroeconomic modeling. In NBER Macroeconomics Annual 2000, Volume 15(pp. 139-182). MIT Press.

19. Morris, S., \& Shin, H. S. (2005). Central bank transparency and the signal value of prices. Brookings Papers on Economic Activity, 2005(2), 1-66.

20. Phelps, Edmund S. "Introduction," in E. S. Phelps et al., eds., Microeconomic foundations of employment and information theory. New York: Norton, 1970, pp. 1-23.

21. Phelps, Edmund S. "The Trouble with Rational Expectations and the Problem of Inflation Stabilization,” in R. Frydman and E. S. Phelps, eds., Individual forecasting and aggregate outcomes. New York: Cambridge University Press, 1983, pp. 31-40.

22. Romer, C. D., \& Romer, D. H. (2000). Federal Reserve Information and the Behavior of Interest Rates (Digest Summary). American Economic Review,90(3), 429-457.

23. Svensson, Lars E. O. (2006). Social Value of Public Information: Comment: Morris and Shin (2002) Is Actually Pro Transparency, Not Con, American Economic Review, 96(1), pp. 448-452.

24. Ui, T. (2003). A note on the Lucas model: iterated expectations and the neutrality of money. Unpublished paper, Yokohama National University.

25. Walsh, C. E. (2010). Monetary theory and policy. MIT press.

26. Woodford, M. (2005). Central bank communication and policy effectiveness (No. w11898). National Bureau of Economic Research. 